\title{
CONTROLE DOMICILIAR DO PREMATURO *
}

\author{
Domingos Conrado **
}

REBn/01

CONRADO, D. - Controle domiciliar do prematuro. Rev. Bras. Enf.; DF, 30 : 227-236, 1977.

\section{INTRODUÇÃO}

A Organização Mundial da Saúde (OMS), quando nos fala de um "bem estar físico, mental e social", pretende apresentar a saúde como um valor, uma entidade que transcende a dimensão simplesmente física da vida, mas encerra em sua essência outros elementos, dentre. os quais salientamos os fatores sócioestruturais, regionais e culturais dos indivíduos em relação à saúde.

O Brasil, na condição de país em desenvolvimento, nos mostra uma população em rápido crescimento, com pirâmide populacional demonstrativa de absoluta prevalência de grupos jovens, acusando altas cifras de natalidade.

Apesar da queda recente na mortalidade geral e infantil, na qual se observa também a diminuição da mortalidade peri-natal a morbimortalidade de um ano de idade continua alta sobretudo quando analisada frente a certas regiōes com maior grau de desenvolvimento.

O baixo nivel de educação tem sido um fator decisivo na manutenção do "status quo" e paralelamente observase uma conscientização mínima do problema por parte da população. Decorre assim, pouca valorização e freqüência dos serviços de pré-natal, advindo daí graves danos para a mãe e a criança.

A prematuridade tem sido uma das conseqüências diretas dessa situação. Este problema tem preocupado as autoridades sanitárias e particularmente em nosso hospital há uma preocupação efetiva com o problema, de tal modo que dentre os vários programas e projetos existentes, o controle domiciliar ao prematuro ocupa um lugar de proeminência.

\section{2 - CONSIDERAÇÓES GERAIS}

O Hospital do Servidor Público Estadual (HSPE), subordinado ao Instituto

- Trabalho apresentado no $10^{\circ}$ CONGRESSO SULAMERICANO DO CICIAMS XXVII CONGRESSO BRASILEIRO DE ENFERMAGEM.

* Enfermeiro Hospitalar do Servidor Público Estadual - S. Paulo. 
de Assistência Médica ao Servidor Público Estadual (IAMSPE), é uma entidade que visa prestar assistência médica aos funcionários públicos estaduais e seus dependentes, através de todas as suas especialidades médicas e paramédicas, proporcionando aos mesmos assistência curativa e preventiva. O Hospital conta com uma capacidade de 1.000 leitos, com um movimento ambulatorial de 3.000 consultas diárias. A população atingida é muito heterogênea, com diferentes níveis sócio-econômicos e culturais, espalhado por todo o Estado, englobando cerca de 100 categorias profissionais, com prevalência em 1973, de professores secundários, escriturários e serventes, entre os registrados como novos.

O Setor de Enfemagem de Saúde Pública do HSPE contribui na promoção cảa saúde prevenção e controle de doenças aos usuários do Hospital. Dentro dessa perspectiva, a Enfermagem partic.́pa ativamente de uma série de programas e projetos desenvolvidos no hospital e na comunidade. Essas atitudes são levadas a efeito por uma equipe multiprofissional contando com os seguintes profissionais:

- Médicos, enfermeiros, assistentes sociais, nutricionistas, psicólogos, fisioterapeutas e outros.

Objetivando uma melhor racionalização do trabalho e conseqüentemente maior produtividade, nos anos de 1970 e 1973, foi feito um zoneamento da Grande São Paulo (Capital e Municíplos), inicialmente em quatro áreas e posteriormente em oito, designando a responsabilidade de cada uma delas a um enfermeiro de Saúde Pública pelo atendimento global (programas e projetos), não somente aos usuários do IAMSPE, como também daqueles que direta ou indiretamente afetam a comunidade em que vivem, devido a problemas de saúde.

\section{3 - CONTROLE DOMICILIAR AO PREMATURO}

Dentre os vários projetos existentes, salientamos o Controle Domiciliar ao Prematuro, como uma das grandes preocupaçōes da Saúde Pública desse Hospital.

3.1 - Histórico e Objetivos: Inicialmente achamos oportuno relembrar algumas consideraçōes a respeito da criação desses projetos em 6-10-70.

Tendo sido notado que vários prematuros, após longa permanência no berçário, onde cercados dos maiores cuidados, retornavam pouco tempo depois em mau estado geral e nutritivo, sendo necessário, na maioria das vezes, longa internação para tratamento e recuperação; resolveu a Direção do Hospital, incentivar os Serviços de Neonatologia, Saúde Pública e Serviço Social, a juntos elaborarem um programa para atendimento domiciliar ao prematuro, o qual teve seu início em 5 de outubro de 1970.

Com isto objetivou-se:

a) antecipar também a alta do Berçário para quando o prematuro atingisse um peso de $2.300 \mathrm{~g}$ (anteriormente o limite mínimo era de $2.500 \mathrm{~g}$ ), reduzindose o tempo de permanência no Berçário, com diminuição do rísco de infecção cruzada e redução do custo de hospitalização, pois grande parte dos casos se enquadrav $2 m$ dentro dos critérios para isençāo de pagamento, conforme estudos da seção de Serviço Social Médico.

b) uma fiscalização da observância pelos familiares das orientaçōes higiênico-sanitárias, dos cuidados e da ministração adequada da alimentação e medicamentos prescritos, tentando-se deste modo reduzir ao mínimo o retorno do prematuro ao hospital, em condiçōes nuuitas vezes irrecuperáveis ou de prolongado tratamento hospitalar.

c) proceder-se à vacinação completa, aplicada durante as visitas, cujo bene- 
fício, é óbvio, dispensando maiores comentários.

d) eliminar o retorno do prematuro aós ambulatórios para consultas de rotina e orientaçāo alimentar, reduzindo a possibilidade de contágio no ambiente hospitalar, reservando-se os retornos apenas a consultas de real necessidade.

Inicialmente o programa foi desenvolvido por uma equipe de quatro médicos do SERVIÇO DE NEONATOLOGIA, quatro enfermeiras de Saúde Pública, duas auxiliares de enfermagem e duas assistentes sociais, recebendo visitas médicas apenas as crianças residentes no municipio de São Paulo. Os médicos, além da visitação domiciliar, continuavam exercendo plenamente as suas funçōes no Berçário e Ambulatório de Neonatolugia, dispensando apenas quatro horas semanais cada um para as visitas domiciliares (o que permanece inalterado). Porém, com a admissão de 2 (dois) médicos para o SERVIÇO DE MEDICINA SOCIAL, exclusivamente para o Programa de Controle Domiciliar do Prematuro, passaram a receber visitas médicas todas as crianças matriculadas no Programa. Receberam alta do Programa sem visita médica 16 casos, residentes fora do municípiơ de São Paulo $(5,2 \%)$. Constatouse ainda que devido ao esquema de visitação proposto inicialmente (visitas quinzenais até dois meses de idade, mensais até seis meses e bimestrais até doze meses), nāo se conseguia dar cobertura a todos os casos, tendo-se entāo, adaptado us esquemas de acordo com as necessidades de cada caso em particular.

Como tivesse sido observado que certo número de prematuros, apesar dos cuidados e medicamentos prescritos, apresentavam acentuado grau de desnutrição e/ou dificuldade de ganho ponderal, foi aventada a possibllidade de se introduzir à dieta um alimento proteico de fácil digestibilidade e assimilaçāo. Tendo já sido comprovado no Berçário do Serviço de Pediatria que a adiçāo de carnes pre- viamente digeridas e liofilizadas, às mamadeiras de prematuros e crianças disrépticas apresentava bons resultados, resolveu-se introduzir o seu uso ao grupo de prematuros acima citado, tendo então - Serviço de Nutrição e Dietética emprestado sua colaboração ao Programa a partir de maio de 1972.

Os problemas e dificuldades eram solucionados em reuniōes inicialmente semanais e posteriormente quinzenais, com o diretor do Hospital, onde, além do andamento do Programa eram apreciadas sugestões para sua melhoria e entrosamento com os diversos setores do Hospital.

3.2 - Constituição da Equipe e Frequiência de Visitas: Atualmente a Comissāo de Controle Domiciliar ao Prematuro (CCDP), é constituída basicamente por:

- Médicos do Serviço de Medicina Social e Pediatria.

- Enfermagem de Saúde Pública, constituída por enfermeiras de Saúde Pública (8) e auxiliares de enfermagem (2), que acompanham as visitas médicas.

- Serviço Social Médico, constituído por 2 assistentes sociais, nutricionistas (2).

Dos vários componentes da equipe, apenas os médicos do Setor de Medicina Social e as assistentes sociais do Setor de Comunidade se dedicam exclusivamente aos programas. As enfermeiras de Saúde Pública ministram ainda orientações e noções de puericultura, assim como cuidados, tais como: curativos junto aos Ambulatórios de Neonatologia e Puericultura do Serviço de Pediatria. Além disso trabalham também no Serviço de Assistência Domiciliar (casos de diabetes, tuberculoses, hepatites, crônicos, etc.).

As nutricionistas prestam serviços aincia no Setor de Parto Psico-Profilático e na elaboração do programa a ser de- 
senvolvido no Horto Florestal. Os médicos do Serviço de Neonatologia prestam atendimento normal no Berçário e Ambulatório de Neonatologia.

$O$ atual coordenador acumula ainda $o$ cargo de médico visitador.

Quanto à freqüência de visitas domiciliares, cada profissional da equipe obedece uma rotina que apresentamos a seguir:

\section{FREQUENCIA DE VISITAS:}

2 vezes por semana cada médico do Setor de Medicina Social;

2 vezes por semana cada enfermeira da Saúde Pública;

2 vezes por semana cada assistente social;

1 vez por semana cada médico do Serviço de Neonatologia;

1 vez por semana cada nutricionista.

\section{3 - Sistema de Atendimento}

3.3.1 - Critério para admissão: Sāo admitidos ao Programa:

a) Todos os recém-nascidos com peso inferior a $2.500 \mathrm{~g}$, nascidos neste Hospital e residentes na Capital ou nos $\mathrm{Mu}$ nicípios adjacentes.

b) Todos os recém-nascidos com peso inferior a $2.500 \mathrm{~g}$, nascidos fora do HFMO e residentes na Capital ou Municipios vizinhos, que procuram o Hospital até aos seis meses de idade.

c) Recém-nascidos com peso superior a $2.500 \mathrm{~g}$, nascidos no HFMO, ou não, cujo irmão gêmeo se enquadre nos itens anteriores.

Todos os recém-nascidos que se enquadram nos itens acima especificados são admitidos no Programa independentemente do grau de cultura ou situação sócio-econômica dos pais, obedecendo-se posteriormente ao seguinte:
3.3.2 - Critérios para prioridade de visitação:

a) Doenças ou má formações congênitas que requeiram controle e seguimento após a alta do Berçário.

b) Precariedade sócio-econômica e/ou baixo nível mental ou cultural dos pais.

c) Presença de problemas familiares que possam indiretamente comprometer a saúde do prematuro.

d) Más condiçōes sanitárias habitacionais.

e) Gemelaridade.

Quando da procura ao hospital, ou nos dias após o nascimento, a mãe é entrevistada por uma assistente social que anota endereço e vias de acesso, como também inquire sobre a constituição da fúmilia, condições sócio-econômicas e situação funcional do contribuinte, procurando ao mesmo tempo saber se existem problemas de relacionamento familiar ou hábitos que porventura indiretamente afetem o bem-estar do recémnascido, providenciando para que sejam tomadas as medidas necessárias antes da alta do RN.

Ao mesmo tempo, é a mãe entrevistada por uma enfermeira de Saúde Pública que inquire sobre o tipo de habitação e condiçōes sanitárias, tais como: tipo de água consumida e melhoramentos existentes, além do preenchimento dos dados referentes ao RN na ficha apropriada. Já nessa ocasiāo ou em dias subseqüentes ministra orientação à mãe sobre os cuidados e técnicas de alimentaçāo do RN.

Após a alta do Berçário, ou antes disso, se necessário, iniciam-se as visitas domiciliares, preliminarmente pela enfermagem ou assistente social para comprovação dos dados obtidos pela entrevista, além da ministração das orientaçōes necessárias e obtenção dos dados antropométricos do RN. Caso seja notada alguma anormalidade é então antecipada a visita médica programada. 
Na visita médica além da avaliação das condições de saúde do prematuro é feito o controle dos dados antropométricos, prevenção e deteç̧ão precoce de doenças, assim como verificações da adequaçāo da alimentaçāo para a idade. Caso haja necessidade de consulta ou tratamento especializado, estas crianças são encaminhadas ao HFMO.

Com a finalidade de se evitar uma permanência prolongada no Hospital, devido à espera nas clínicas especializadas, ou quando procurado o Serviço cie Emergência, idę̧lizou-se o fornecimento de um cartāo diferente do comum (de cor azul), com os dizeres: PREMATURO - ATENDIMENTO URGENTE. Por sua vez, também o prontuário médico, para ser mais prontamente localizado, recebeu uma tarja de coloração verde.

Ambos sāo automaticamente substituídos ou retirados quando a criança recebe alta do Programa. As visitas são então programadas de acordo com as necessidades, sendo mais freqüentes quanto maior seja o grau de precariedade sócioeconômica ou não observância dos cuidados e da medicaçāo prescrita, defeitos ce técnica no preparo da alimentaçāo ou más condições de desenvolvimento ou de saúde do prematuro.

Quando necessário a assistente social também intensifica suas visitas além de dar andamento ao processo de isenção de pagamento para fornecimento de medicamentos, leite ou exames.

Nos casos de máu desenvolvimento apesar da observância das instruçōes, tr. nta-se a introduçāo de um complemento protéico (carne liofilizada ou Proteimax), recebendo então o prematuro também a visitação da nutricionista da equipe para avaliação e controle.

Caso sejam notados distúrbios ou doenças nos familiares, sāo estes encaminhados ao Hospital, pelo médico ou enfermeira visitantes.
A partir de 1975, objetivando uma melhor avaliaçāo do desenvolvimento nornial do prematuro, foi introduzido como rotina do Programa a realização de exames de sangue, urina e fezes por ocasiăo do $3 .^{\circ}$ e do $9 .^{\circ}$ mês, sendo que no $3 .^{\circ}$ mês, são realizados os seguintes exames:

Proteinograma

Eritograma

Urina tipo $I$.

E, no $9 .^{\circ}$ mês:

Proteinograma

\section{Eritograma}

Urina tipo I

Cálcio e Fósforo

Fosfatase Alcalina

Parasitológico.

3.3.3 - Critérios para alta: As crianças recebem alta normalmente ao completarem 12 meses de idade. Nessa época, encontram-se já devidamente vacinadas e com orientação de alimentação adequada à idade.

Caso sejam notados: mau desenvolvimento, dificuldade de adaptaçāo às orientaçōes ministradas ou precariedade sócio-econômicas com reflexo sobre a saúde e bem-estar do prematuro, sāo estes mantidos no Programa até obterse melhoria dessas condições.

Deixam também de receber visitação os seguintes casos:

a) Mudança para o interior do Estado.

b) Transferência para a creche.

c) perda de direito à assistência médica do IAMSPE.

d) Recusa em obedecer às orientações ou rotinas do Programa.

e) Quando apresentem condiçōes sócio-econômicas satisfatórias, com acompanhamento por pediatra particular cujas orientaçōes colidam com a rotina do Programa. 


\section{4 - CONTROLE PELA ENFERMAGEM DE SAƯDE PÚBLICA (ROTINAS).}

4.1 - Admissão do Prematuro no Berçário de Neonatologia e entrevista com a mãe no Serviço de Obstetricia:

a) A admissão do prematuro para o controle de enfermagem estará a cargo da enfermeira de Saúde Pública responsável pela educação sanitária do Puerperio.

b) A enfermeira responsável por esta tarefa, deverá entrar em contato com o Serviço Social Médico do Programa para receber a ficha aberta pelo assistente social e o estudo dos casos novos. A ficha aberta pelo Serviço Social Médico deverá trazer preenchidos corretamente os seguintes itens:

1 - Identificação.

2 - Situação funcional.

3 - Situação familiar.

4 - Parecer do Assistente Social do Programa.

c) A enfermeira responsável por esta tarefa, irá ao Berçário, de segunda à sexta-feira, no período da manhā, a fim de entrar em contato com a enfermeira responsável e secretário do Serviço de Neonatologia, e iniciar o preenchimento dos "Dados sobre os pacientes e outros Esclarecimentos".

D) A seguir, a enfermeira, após o primeiro contato com o Serviço de Obstetrícia, desenvolverá as seguintes atividades:

A) Exposiçāo dos objetivos do Programa, em especial o atendimento médico e de enfermagem.

B) Início do preenchimento do item "Levantamento Domiciliar"e dos subitens que possam ser recolhidos na entievista.

C) Orientação à puérpera para cuidados de higiene pessoal, alimentação, exercícios e outras orientações sobre educação sanitária.
D) Orientação à puérpera e familiares sobre o preparo ambiental e recepção do p:ematuro, incluindo-se os cuidados gerais dispensados ao mesmo, que são:

1 - Banhos e cuidados de higiene do bebê.

2 - Roupas.

3 - Higiene ambiental.

4 - Alimentaçāo: fervura de água e utensilios, cuidados com as mamas $e$ demonstração do preparo de mamadeires.

E) Orientar sobre a necessidade do Registro Civil da criança antes da alta cio Berçário.

e) Aviso à enfermeira responsável pelo Controle Domiciliar do Prematuro dos casos especiais que precisam visita domiciliar antes da alta do bebê, definindo o problema cia causa e fornecendo dados completos.

f) Após a alta médica do prematuro no Berçário, acabará de preencher os sub-itens "Intercorrências, etc.", "Condiçōes de alta, Peso e Data", do item n.. 3.

g) A ficha preenchida será entregue às enfermeiras responsáveis pelo Controle Domiciliar do Prematuro.

\section{2 - Admissão de Prematuro nascido} fara do H.S.P.E.:

a) Os prematuros nascidos fora do Hospital poderão ser admitidos no Programa antes de atingirem os 6 meses de idade.

b) A admissão será efetuada através do Serviço de Pediatria: Enfermarias e Ambulatórios.

c) A enfermagem tomando conhecimento do caso, e após iniciar o preenchimento dos itens 3 e 4, colocado o local do nascimento e os sub-itens que possam obter, encaminhará o caso ao Serviço Social Médico do Programa, para entrevista com a mãe ou responsável e preenchimento dos itens correspondentes. 
d) O Serviço Social Médico, spós o preenchimento dos referidos itens, encaminhará a ficha à enfermagem responsável pelo controle domiciliar.

e) Caso o prematuro esteja internado ro Berçário de Pediatria, a enfermeira recponsável pelas atividades de Saúde Pública da Pediatria, entrevistará a mãe, por ocasiāo da visita à criança, ou convccará os pais, caso necessário, para orientação e explicação do objetivo do Programa.

f) Por ocasiāo da alta da criança a cnfermagem responsável pelo controle domiciliar receberá através da enfermeira de Saúde Pública da Pediatria, ficha constando: data e condiçōes da alta, intercorrências durante a internaçāo e ciiagnóstico definitivo.

\section{3 - Atividades correspondentes d̀} Enfermagem Responsável pelo Controle Domiciliar:

a) A enfermeira responsável pelo Controle Domiciliar dos Prematuros, receberá a ficha própria, Folha I, entregue pela enfermeira responsável pela admissão do puerpério, na Pediatria ou Serviço Social Médico.

b) Recebida a ficha, designará a zona, cie acordo com o lugar de residência.

c) Será aberto o prontuário-prematuro, preenchido corretamente todos os itens das folhas 2,3 e 4 da capa, esta com caneta de côr correspondente à zona.

$$
\begin{array}{cl}
\text { Zona } & 1 \text { - verde. } \\
" & 2 \text { - preto. } \\
" & 3 \text { - azul. } \\
" & 4 \text { - vermelho. }
\end{array}
$$

d) Será aberta a ficha-índice pelo nume completo do contribuinte, antecipando-se o último sobrenome e arquivando-se pelo mesmo. Nesta ficha deverá constar, além do nome do contribuinte, número da ficha do prematuro, número do prematuro-geral e endereço.

e) Será aberta a ficha rotativa individual do prematuro colocando o nome cá mãe do bebê, caso este ainda não tenha Registro Civil, preenchendo-se corretamente todos os itens.

f) A ficha rotativa individual, após preenchida, será colocada no fichário da zona correspondente, para programação da primeira visita domiciliar da enfermeira responsável pela zona, e o prontuário do prematuro no arquivo em ordem dígito-terminal e dentro deste, por ordem de numeração.

g) A primeira visita domiciliária da enfermeira será efetuada dentro dos 30 dias após alta do Berçário, excetuando casos prioritários que deverāo ser efetuadas no menor intervalo possivel.

h) Para programaçāo das visitas domiciliária, enfermeiras e médicos estabelecerāo prioridades:

1 - Casos gemelares.

2 - Casos com problemas de saúde nos familiares.

3 - Condições da alta do Berçário do prematuro.

4 - Coincidir com as datas das vacinas.

5 - Problemas de educação sanitária dos familiares.

6 - Proximidades dos domicílios.

i) Os pedidos de viatura para visita domiciliar são programados com antecedência, assinando ficha de assiduidaċe e no dia da visitaçāo domiciliária bastará um telefonema para que o carro seja liberado.

j) Após programaçāo requisitar os prontuários do Arquivo Médico de véspera, devendo ser revisado no dia da visita domiciliar pela pessoa que efetuar a visita.

1) Preparo do material para levar ao domicílio:

Bolsa contendo: termômetro, fita métrica, sabão, papel-toalha, gaze, esparadrapo e nitrato de prata;

Régua antropométrica;

Balança, e

Isopor com vacinas. 
m) Na primeira visita domiciliar da enfermeira, após identificaçāo será completado o Levantamento Domiciliar e feito diagnóstico de enfermagem.

n) Feita a parte burocrática serão dados os cuidados de enfermagem, após preparo do material contido na mala de Saúde Pública e desinfecção das mãos.

\section{ATIVIDADES:}

A) Peso.

B) Medidas antropométricas.

C) Temperatura.

D) Exame geral da criança, curativo umbilical, se necessário, e cuidados de higiene.

E) Demonstraçōes de técnicas:

- cuidados do vestuário;

- cuidados da habitação;

- preparo da mamadeira e alimentos;

- para administração de alimentos;

— posição do bebê.

F) Orientação sobre alimentação, hidratação e horários.

G) Orientaçōes gerais de educação sanitária para o bebê.

h) Levantamento e orientações gerais do estado de saúde dos outros membros da família e anotação de casos e encaminhamento aos recursos da comunidade, quando necessário.

I) Verificação do comportamento dos membros da familia em relação ao prematuro, em particular do comportamento dos irmãos mais velhos.

J) Verificação e orientação do comportamento dos pais, para com os irmãos mais velhos.

L) Verificação das vacinas aplicadas a outros membros da familia.

M) Verificar se a criança passou os 2 meses de idade, peso acima de $2.500 \mathrm{~g}$ e estiver em condiçōes de aplicar a primeira dose da vacina Triplice $+\mathrm{Sa}-$ bin.
N) Anotaçōes de todas observaçōes nos itens correspondentes da folha $n .^{\circ} 2$ e na folha única n. 3 do prontuário prematuro.

O) Guardar todos os utensílios usados.

P) Após efetuada a visita domiciliar, informar 20 médico responsável se o caso requer visita médica com prioridade. Após cada visita domiciliar, se fará outro plano para as visitas domiciliárias subseqüentes.

Q) Após a alta do atendimento domiciliar, fazer o resumo do atendimento e anexar no prontuário médico.

R) Durante a última visita domicillar dar as devidas orientaçōes e os respectivos encaminhamentos, acompanhados cos relatórios necessários:

- encaminhar ao posto de imunizações para reforço das vacinas;

- encaminhar à Pediatria para continuidade do controle da saúde.

S) Trocar o cartão azul de consulta de emergência do prematuro, pelo cartão branco normal de consulta.

\section{ATIVIDADE DE ENFERMAGEM DE SAƯDE PUBLICA DURANTE \\ 5 ANOS DE CONTROLE DOMICILIAR DO PREMATURO}

A concientizaçáo gradativa e a preocupaçāo que vem atingindo organizaçōes de saúde frente a programas de saúde global do indivíduo, fizeram com que neste $5 .^{\circ}$ ano de atividades em relação ao programa de prematuros procurássemos desenvolver um trabalho de equipe ccm maior entusiasmo e dedicação.

Os resultados obtidos em anos anteriores e a preocupação que vem tendo o HSPE em desenvolver trabalhos preventivos, cada vez mais vem comprovar a validade de tipos de programas como o controle domiciar do prematuro.

Ao completarmos 5 anos de atividades de enfermagem no controle domiciliar do prematuro, sente-se a consolidação do 
programa o que pode ser notado pelo resultado obtido e pela excelência dos serviços prestados, quer pela enfermagem, quer por outros profissionais constituintes da equipe.

Com o intuito de apresentar uma visão objetiva do trabalho desenvolvido, podemos constatar inicialmente um aumento gradativo no número de prematuros controlados, denotando não apenas um agravamento da problemática do prematuro, mas, sobretudo que a procura de assistência médica a este hospital nos últimos anos aumentou, consideravelmente, observa-se que no transcurso de 5 anos uma maior porcentagem de crianças que receberam alta, ao atingirem o limite de idade estabelecida (12 meses) e que as altas por idade engloba um total de $\mathbf{8 4 , 7 \%}$ sobre as altas compulsórias. Por alta compulsória entende-se os seguintes casos:

\section{- Alta a pedido}

- Mudança para o interior

- Perdas de direito ao Hospital

- Desinteresse da família.

Quando falamos de admitidos englobamos as crianças nascidas com peso acima de $2.500 \mathrm{~g}$ e os gemelares. $O$ número ínfimo de óbitos (21 sobre 977 controlados) vem comprovar a eficiência do programa satisfazendo plenamente um dos seus maiores objetivos, qual seja: a redução da mortalidade do prematuro. Esta melhoria reflete nitidamente um melhor resultado obtido devido ao maior entrosamento da equipe proporcionando melhores condiçōes de atendimento pela experiência acumulada nos 5 anos de atividades.

O aumento das visitas domiciliares, tem sido um dos fatores determinantes desse resultado obtido. Podemos observar que em 1975 chegamos a um total de 5.617 visitas de enfermagem, seguidas de 2,890 visitas médicas e em número mais reduzido visitas do serviço social e nutrição, visto que esses profissionais não fazem um controle sistemático domiciliar.

O número de visitas de enfermagem vem comprovar a importância desse profissional no controle de saúde do prematuro e da eficiência do programa. $O$ aumento do número de visitas domiciliares de enfermagem, é decorrente em parte da reestruturação do zoneamento efetuado pela Saúde Pública, conseguindo-se através da melhoria de planificação um melhor rendimento além da economia de pessoal e viaturas. Podemos constatar que a quase totalidade dos prematuros com alta em torno de 99 a $100 \%$, receberam as vacinas básicas: Tríplice, Sabin, Anti-variólica e Anti-sarampo. O fato de não conseguirmos $100 \%$ de vacinação completa deve-se a processos mórbidos durante as visitas, que impediam a vacinação.

A grande diferença no número de aplicaçōes das vacinas completas, em relação a vacina trivalente (Anti-cachumba, Anti-rubéola e Anti-sarampo) ou MMR, deve-se ao fato desse tipo de vacina só encontrar aplicação após os 12 meses de idade, quando a grande maioria das crianças já receberam alta do programa, e também a falta temporária da mesma. As crianças que não recebem a vacina são encaminhadas 20 Posto de Imunização do Hospital em data oportuna afim de completar esquema de vacinação.

Em relação ao aproveitamento quanto às orientaçōes de educação sanitária dadas às famílias, procurou-se estabelecer 4 niveis conceituais assim classificados: Muito bom, Bom, Regular e Péssimo, sendo que no momento pensa-se numa reformulação desses conceitos, em uma nova classificação a partir de critérios mais objetivos.

Estabeleceu-se como ótimo, o aproveitamento das famílias que além do interesse e seguimento de todas as instruções, mudaram os hábitos referentes à saúde e aproveitamento dos recursos disponíveis para benefício do prematuro e 
outros membros da família. Como Péssimo aqueles casos que não obstante receberem visitas mais frequentes e apesar da maior insistência dos diversos membros da equipe, não foi conseguida alteração dos hábitos e condições higiênicas, nem interesse pelo atendimento. Nos critérios Bom, Regular e Péssimo classificam-se as demais familias, segundo seu maior ou menor aproveitamento. Foram estabelecidos critérios que nos dessem melhores subsídias para uma avaliação mais completa, após a avaliação inicial e a avaliação fínal, viu-se que o resultado obtido foi satisfatório, pois a mudança de comportamento a partir das orientações dadas foi bem perceptivel.

Em relação as atividades desenvolvidas, teríamos que especificar o que elas encerram pois, quando falamos de entrevistas queremos englobar as realizadas no HSPE, e no Domicílio, quer seja com a mãe, quer com outros membros da familia. Quanto as orientaçōes, as entendemos como orientaçōes sobre alimentos, higiene e vacinas.

Em relação aos cuidados de enfermagem computamos: preparo da alimentação, curativos umbilicais e outros, cuidados de higiene, medidas antropométricas, peso, temperatura, aplicaçāo de injeçōes e colheita de material.

Quanto aos fornecimentos, os estendemos em relação aos folhetos educativos, cloro, medicaçø̄es e alimentos.
Além desses dados computados, deveríamos considerar que para cada criança que é visitada é feita uma revisão de Prontuário Médico, e um Relatório após a visita. Portanto, é um dado estatístico que deve ser levado em consideração numa análise global.

\section{CONCLUSAO}

O Controle Domiciliar do Prematuro vai-se consolidando a cada ano que passa.

O Zoneamento tem propiciado sobretudo a enfermagem, um melhor equacionamento do trabalho, melhor aproveitamento de tempo, e melhor atendimento ao prematuro.

Houve bom grau de aproveitamento das orientaçōes dispensadas, sobretudo quando passamos a uma avaliação no início e no final do programa.

A introdução de rotina de exames de laboratório tem propiciado um controle melhor da saúde do prematuro.

A Educação Sanitária tem sido um dos pontos básicos do programa e há uma preocupação constante em aprimorá-la.

Após um ano de atendimento o prematuro tem apresentado um bom desenvolvimento Neuro-psicomotor, trazendo para a Comissão de Controle Domiciliar uma satisfação muito grande.

Desejamos que o relato desta experiência incentive a criação de outros grupos de trabalho revertendo-se em benefício para a manutençāo da VIDA.

\section{BIBLIOGRAFIA}

MONTENEGRO, Dr. Júlio de Menezes e Col "Relatório Comparativo de Atividades de 1970-1971, da Comissāo de Controle Domiciliar de Prematuros" H.S.P.E. 1972.

MONTENEGRO, Dr. Júlio de Menezes e Col "Relatório Comparativo de Atividades de 1971-1972, da Comissão de Controle Domiciliar de Prematuros" H.S.P.E., 1973.

MONTENEGRO, Dr. Júlio de Menezes e Col "Relatório Comparativo de Atividades de 1972-1973, da Comissāo de Contro!e
Domici.iar de Prematuros" H.S.P.E., 1974.

Relatório das Atividades de Enfermagem de Saúde Pública de 1973-1974, do Controle Domiciliar de Prematuros H.S.P.E. - 1974.

Relatório das Atividades de Enfermagem de Saúde Pública de 1974-1975, do Controle Domiciliar de Prematuros H.S.P.E. - 1976.

Relatório Estatístico do H.S.P.E. - 1973 Serviço de Arquivo Médico e Estatística. Relatório Estatístico do Setor de Enfermagem de Saúde Pública - 1970 1975 - H.S.P.E. 